that it produces compulsive sexual activity in male animals from the experiments by Ferguson et al, 1 Tagliamonte et $a l^{2}{ }^{2}$ Shillito et $a^{3},{ }^{3}$ and Gessa et $a l^{4}$ The specificity of this action is demonstrated by the fact that the sexual excitement induced by PCPA is inhibited by administration of 5-HTP. Gessa and Tagliamonte ${ }^{5}$ have hypothesised a disturbance of 5-hydroxytryptamine (5-HT) as the causal element in sexual dysfunctions. Patients with multiple sclerosis treated by Hyyppa ${ }^{6}$ with Ltryptophan did not show any significant change in sexual motivation. Hyyppa et al ${ }^{7}$ also administered the amino-acid to normal volunteers, and although no change in sexual behaviour or arousal was noted, transient decreases in plasma gonadotrophins were found after each dose. Finally, Sicuteri et al ${ }^{9}$ observed that L-tryptophan was capable of diminishing excessive sexual responsiveness in patients suffering from hypersexuality.

It is is difficult, therefore, to understand the cause of the hypersexuality seen after Ltryptophan in Drs Egan and Hammad's patients. It should be noted, however, that four out of five of them were suffering from schizophrenia and were being treated with phenothiazines in addition to the amino-acid. Bender ${ }^{9}$ has observed that phenothiazines have a complex action on serum tryptophan in schizophrenics; it appears that in such patients they reduce brain serotonin synthesis, whereas in rats they have the reverse effect. It might be postulated that, in similar fashion, administered L-tryptophan may have an atypical effect in schizophrenic patients receiving phenothiazines.

L-Tryptophan has so far been mainly indicated for the treatment of affective disorders and we believe that it has been used very little in the management of schizophrenia. Smuthies ${ }^{10}$ has recently drawn attention to its possible application in schizophrenic patients. If his advice is followed hypersexuality may become a more commonly reported side effect.

ALAN D BRoADHURST BAPUjI RAO

West Suffolk Hospital,

Bury St Edmunds

' Ferguson, J, et al, Psychophysiology, 1969, 6, 221.

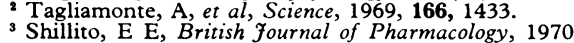
38, 305.

- Gessa, G L, et al, Nature, 1970, 227, 616 Pharmacolognd Tagliamonte, A, Sexual Behaviour: Pharmacology

Hyyppa, M T, British Medical fournal, 1976, 2, 1073 Hyyppa, M T, et al, Presentation at International Congress of Pharmacology, Helsinki, 1975.

Sicuteri, F, et al, Presentation at International Congress of Pharmacology, Helsinki, 1975.

10 Bender, D A, Lancet, 1976, 2, 427.

\section{Community self-care}

SIR,-For the past two or three years we have had a community care scheme which, is organised by the local inhabitants. It has provided a great deal of help in our practice in that there is a panel of volunteer drivers who will take visitors to hospital, collect prescriptions for the housebound, and also bring patients to the health centre and even provide immediate companionship in a family crisis.

We try to make reasonable use of their services and not abuse them. The local people are encouraged to offer their services for driving, gardening, phone-answering, etc. There is a phone number (easily remembered) to be used for offers and requests. It is not intended as a "them and us" arrangement but one in which there are times for giving help and times for receiving it (in one form or another). Finally, it is not used as a system for avoiding proper medical responsibilities but as an aid to improving care. It is known as LINK (presumably "the bond between").

The details are beyond the scope of a shor letter, but further inquiries are welcomed.

\section{R J COCKeriLI}

The Health Centre,

Oxted, Surrey RH8 0BQ

\section{Ferrous sulphate: danger to children}

SIR,-We were disappointed to receive a recommendation from the DHSS recommending the use of ferrous sulphate. The British National Formulary 1976-1978 is quoted as saying: "The dosage of elemental iron should be at least $100 \mathrm{mg}$ daily. Ferrous sulphate in tablet form is the preparation of choice."

Although ferrous sulphate is the cheapest iron preparation, it is also the most toxic. The green, sugar-coated tablets attract small children, who may suffer haemorrhagic necrosis of the gastric or jejunal mucosa, live damage, and sometimes death after swallowing them. A very common sequence is that the toddler gains access to his mother's iron tablets, prescribed for her when she is pregnant again.

In 1966 four infants under 3 years of age were admitted to our children's ward with ferrous sulphate poisoning. All were the offspring of our antenatal patients. Three were severely shocked and had gastric haemorrhages and one was left with an hour-glass constriction of the stomach. The ferrous sulphate tablets had been dispensed with a warning in red on the bottle that the tablets were dangerous to children.

Since 1967 the prescription of ferrous sulphate for pregnant women has been forbidden in our obstetric depaitment and local general practitioners have been encouraged to use other preparations. Between January 1967 and December 1975, of 16 children admitted after ingesting iron tablets only three had taken ferrous sulphate and no case was severe.

We are convinced that, at least for pregnant women with young children, it is wise to avoid prescribing ferrous sulphate.

J R SAUNDERS

Department of Obstetrics and A W FERGUSON

Paediatrics, Bedford General Hospital Bedford

\section{FEIBA in haemophiliacs with factor VII} inhibitor

SIR,-Dr G D O Lowe and others (6 November, p 1110) report the successful use of prothrombin complex to secure haemostasis in haemophiliac with an inhibitor to factor VIII. Others have used "factor VIII inhibitor bypassing activity" (FEIBA) in such patient with apparent success, ${ }^{12}$ prompting us to report our experience with this product.

A 32-vear-old man sustained extensive anterior myocardial infarction in 1975. Intractable angina of effort developed subsequently and coronary arteriography revealed stenosis of the anterio descending branch of the left coronary artery. Femoral arterial puncture for this procedure led to extensive bruising of the groin and thigh. Excessive bleeding had also occurred after dental extractions in 1967. Coagulation screening revealed a prolonged activated partial thromboplastin time (APTT) of $70 \mathrm{~s}$ (control $34 \mathrm{~s}$ ) with an otherwise normal profile. The prolonged APTT showed little correction in mixing tests with normal plasma, suggesting the presence of a rapidly acting inhibitor. Levels of all recognised clotting factors were normal when assayed at high dilution.

The APTT of plasma containing moderate numbers of platelets shortened during standing at room temperature for several hours; the association between platelets and the contact phase of coagulation led us to investigate the possibility that the inhibitor might be an abnormal variant of the physiological "anti-Xla." 3 We found that the inhibitor could destroy contact activation product prepared from the patient or from normal subjects very rapidly; it differed in many respects from physiological "anti-Xla."

It seemed likely that FEIBA would bypass the activity of this inhibitor. A trial dose of $15 \mathrm{U} / \mathrm{kg}$ body weight was given. The APTT shortened by $12 \mathrm{~s}$ and this effect lasted at least 72 hours, without evidence of intramuscular coagulation. At operation a vein graft was used to circumvent the stenosis under cardiopulmonary bypass. While on bypass the patient was partially exchangetransfused with six units of bank blood. During closure, after heparin neutralisation, FEIBA $40 \mathrm{U} / \mathrm{kg}$ was given together with fresh blood, platelet concentrate, and fresh frozen plasma. Excellent haemostasis was achieved, with complete normalisation of the APTT, again without evidence of intravascular coagulation although the contribution of FEIBA to haemostasis is uncertain. Postoperative recovery was uneventful and in the four weeks since surgery the APTT has risen slowly to $70 \mathrm{~s}$.

We will report this case and the properties of the unusual inhibitor in more detail elsewhere.

We thank Mr D Ross, who kindly gave us permission to report this case.

TREVOR THOMAS Hugh Williams YVONNE WILLIAMS JILL HUNT

Department of Haematology, Guy's Hospital,

${ }^{1}$ English, P J, Sheppard, E M, and Wensley, R T,
Lancet, 1976, 1, 1299.
${ }^{2}$ English, P J, Sheppard, E M, and Wensley, R T,
Lancet, 1976, 2, 207.
${ }^{3}$ Nossel, H L, and Niemitz, J, Blood, 1965, 25, 712 .

Low molecular weight dextran

SIR,-While in agreement with three of the rules quoted by Dr T G Feest (27 November, $\mathrm{p}$ 1300) for the use of low molecular weight dextran (LMWD), I would disagree with the fourth. He states that LMWD should not be infused at a rate faster than 11 /day. However, this would exclude the very useful effect of dextran 40 in patients who have polycythaemia secondary to chronic hypoxic lung disease, as reported by Harrison et al. ${ }^{1}$ This technique involves withdrawing 21 of blood in $1 \mathrm{~h}$ and giving 11 of dextran 40 simultaneously and another 1 l over the next 6-8 h. This has great symptomatic benefit for secondarily polycythaemic patients, reducing their packed cell volume (PCV) to near normal levels for as long as six months, when the procedure may be repeated. Not only are headaches and lethargy improved, but also pulmonary artery pressure may be reduced and thus right ventricular strain. It has been shown experimentally in dogs that the pulmonary vascular resistance rises exponentially with a rise of PCV. ${ }^{2}$ Simple venesection without dextran 40 may lead to an increased risk of clotting. 